\title{
VARIAÇÃO DA DISTRIBUIÇÃO DO DIÂMETRO ERITROCITÁRIO E DO VOLUME CORPUSCULAR MÉDIO EM CÃES ANÊMICOS
}

\author{
VARIATION OF RED CELL DISTRIBUTION WIDTH AND MEAN CORPUSCULAR \\ VOLUME IN ANEMIC DOGS
}

D. S. GONÇALVES ${ }^{1 *}$, B. F. M. ALMEIDA ${ }^{2}$, S. R. M. BOMFIM ${ }^{2}$, P. C. CIARLINI ${ }^{2}$

\begin{abstract}
RESUMO
A anisocitose é um achado hematológico que rotineiramente é avaliado a partir do volume corpuscular médio (VCM) e da avaliação da morfologia eritrocitária em esfregaços sanguíneos. No presente estudo foi testada a hipótese de que o coeficiente de variação da distribuição do diâmetro eritrocitário (RDW-CV - Red Cell Distribution Width) é um parâmetro hematológico mais sensível na avaliação da anisocitose, considerando-se diferentes graus de anemia e reticulocitose em cães. Foram analisados hemogramas de 102 cães anêmicos e 353 cães controle, realizados em contador hematológico automatizado ABC Vet (Horiba ABX, Paris, França). Os animais anêmicos foram subdivididos conforme o grau de anemia (discreta, moderada e grave) e também de acordo com a resposta medular (resposta nula, discreta, moderada e intensa), por meio da contagem de reticulócitos manual. O RDW-CV apresentou diferença para os subgrupos de animais com anemia moderada e grave, que apresentaram valores maiores, com relação ao grupo con trole e subgrupo com anemia discreta. O maior valor médio de RDW-CV $(14,45 \%)$ ocorreu no subgrupo com anemia grave. No grupo controle o VCM teve valor maior que nos animais anêmicos, isto pode ter ocorrido devido a uma população mista de eritrócitos naquele grupo de animais. Entretanto, não houve diferença do VCM entre os diferentes graus de anemia e reticulocitose. Por isso, o RDW é um indicador de anisocitose mais sensível que o VCM e seu valor é diretamente proporcional ao grau de anemia e reticulocitose; quando associados, a sensibilidade para deteç̧ão de anisocitose em cães anêmicos é maior. O uso de valores de referência estabelecidos pelo próprio laboratório clínico é de extrema importância.
\end{abstract}

PALAVRAS-CHAVE: Anemia. RDW. Reticulócitos. VCM.

\section{SUMMARY}

The anisocytosis is a hematologic finding that is routinely evaluated from the mean corpuscular volume (MCV) and erythrocyte morphology in assessment of blood smears. The present study tested the hypothesis that the coefficient of variation of the red cell distribution width (RDW-CV - Red Cell Distribution Width) is a more sensitive parameter in the evaluation of hematologic anisocytosis, considering different levels of anemia in dogs and reticulocytosis. Blood counts of 102 anemic dogs and 353 control dogs made by automated hematology counter. The anemic animals were grouped according to the degree of anemia (mild, moderate and severe) and also as medullary response by manual reticulocyte count (none, weak, moderate and strong). The RDW-CV was different to the animal groups with moderate and severe anemia, which were higher, compared to the control group and mild anemia. The highest average value of RDW-CV (14.45\%) occurred in patients with severe anemia. In the control group had higher MCV value that anemic animals , this may be due to a mixed population of erythrocytes in that group of animals. However, there wasn't difference in MCV between different degrees of anemia and reticulocytosis. Therefore, the RDW is a more sensitive indicator anisocytosis than VCM and its value is directly proportional to the degree of anemia and reticulocytosis; when combined, the sensitivity for detection of anisocytosis in anemic dogs is greater. The use of reference values established by the clinical laboratory itself is mighty important.

KEY-WORDS: Anemia. MCV. RDW. Reticulocite..

\footnotetext{
${ }^{1}$ Mestranda da Universidade Estadual Paulista "Júlio de Mesquita Filho"- Campus de Botucatu - Departamento de Clínica Veterinária. Autor para correspondência: E-mail: danielesilvano@gmail.com. DCV - FMVZ - UNESP - Botucatu. Distrito de Rubião Júnior s/n Caixa Postal 560. Cep: 18618-970 Botucatu - SP - Brasil. ${ }^{2}$ Doutorando da Universidade Estadual Paulista "Júlio de Mesquita Filho"- Campus de Araçatuba - Departamento de Clínica, Cirurgia e Reprodução Animal - FMVA - UNESP, Araçatuba/SP, Brasil. ${ }^{3}$ Docentes da Universidade Estadual Paulista "Júlio de Mesquita Filho"- Campus de Araçatuba - Departamento de Clínica, Cirurgia e Reprodução Animal - FMVA - UNESP, Araçatuba/SP, Brasil.
} 


\section{INTRODUÇÃO}

A classificação da anemia pela análise morfológica dos eritrócitos e volume corpuscular médio (VCM) permite classificar a anemia como macrocítica, normocítica ou microcítica (HOROLD, 2010). Quantidades elevadas de macrócitos e/ou micrócitos circulantes caracterizam a anisocitose eritrocitária. Nestes casos, o valor do VCM pode ser alterado. Este índice é calculado a partir da relação entre o volume globular (VG) e o número de eritrócitos. Por isso, o VCM é pouco sensível para detecção de anisocitoses (WEISER, 1982). Já a avaliação morfológica dos eritrócitos necessita de um avaliador experiente para não haver diferentes interpretações (SIMEL et al, 1988).

Os contadores hematológicos automatizados por impedância se popularizaram na medicina veterinária nos últimos anos. Devido ao grande número de eritrócitos analisados, estes equipamentos fornecem um valor de VCM mais preciso e calculam o RDW (BESSMAN et al, 1983). A variabilidade dos resultados em diferentes equipamentos é uma limitação para sua utilização clínica, sendo necessário que cada laboratório possua seus valores de referência (HODGES \& CHRISTOPHER, 2011).

A maior sensibilidade do RDW para detectar a anisocitose comparado ao VCM já foi comprovada em humanos (BESSMAN et al, 1983; MONZON et al, 1987; SIMEL, et al, 1988) e é utilizado para avaliação em caninos e equinos (BALARIN, 2001; PERRET, et al, 2001; FLAIBAN \& BALARIN, 2004). Neiger e colaboradores (2002) afirmam que o RDW é acurado para detectar anisocitose em cães e quando interpretado juntamente com o VCM a acurácia se eleva.

A anisocitose ocorre nas anemias regenerativas, quando a medula é responsiva liberando eritrócitos imaturos, com maior diâmetro, na circulação (JAIN, 1993). Independentemente do método analítico para detecção de anisocitose (VCM, RDW, microscopia), estes parâmetros se alteram conforme a resposta medular, porém até o momento não foi investigada a relação entre a anisocitose, o grau da anemia e a reticulocitose na espécie canina.

Tendo em vista a escassez de estudos avaliando a relação entre o RDW, VCM e contagem de reticulócitos, este estudo teve por objetivo principal testar a hipótese de que RDW-CV é um índice hematimétrico mais sensível na avaliação da anisocitose, considerando-se diferentes graus de anemia e reticulocitose. Secundariamente verificar se os valores do RDW-CV e VCM variam conforme o grau de anemia e da reposta medular. Além de estabelecer valores de referência de RDW-CV para espécie canina.

\section{MATERIAL E MÉTODOS}

\section{Seleção dos animais}

Trata-se de um estudo clínico não aleatorizado que utilizou 455 cães sem distinção de sexo, raça e idade, entre um mês e 18 anos, todos atendidos no Hospital Veterinário da Universidade Estadual Paulista
"Júlio de Mesquita Filho" - Campus de Araçatuba.. Destes animais selecionados, o grupo de animais anêmicos foi composto por 102 cães e o grupo de animais controle por 353. Só foram incluídos no grupo controle cães que não apresentassem qualquer alteração no hemograma, dosagem de proteína plasmática total e/ou clínica. No grupo de animais anêmicos foram selecionados cães com VG menor que 37\%, que, posteriormente foram classificados de acordo com o grau de anemia, independentemente de outras alterações hematológicas e clínicas.

\section{Análise das amostras}

Para as análises foram utilizadas amostras de sangue venoso acondicionadas em tubos com anticoagulante ácido etilenodiamino tetra-acético (EDTA) na proporção de $1,8 \mathrm{mg}$ de EDTA/mL de sangue. As contagens totais de eritrócitos, dosagem de hemoglobina e o coeficiente de variação da distribuição do diâmetro eritrocitário (RDW-CV) foram obtidos a partir do contador automatizado de células ABC Vet (Horiba ABX, Paris, França). O VG foi obtido pela técnica do microhematócrito de Wintrobe e dado em percentagem (\%). Preconizou-se esta técnica por sua maior precisão, haja vista que o VG fornecido pelo contador automatizado é obtido por meio de cálculos, além de fornecer resultados de VCM mais fidedigno quando calculado com o VG do microhematócrito. O VCM calculado, conforme Schalm e colaboradores (1975), é expresso em fentolítros (fL). A contagem de reticulócitos foi realizada utilizando-se o corante supravital de Azul de Cresil Brilhante, conforme recomendações de Schalm e colaboradores (1975)

\section{Classificação do grupo de animais anêmicos}

O grupo de animais anêmicos foi subdividido de acordo com os critérios de Harold (2010) para classificar o grau de anemia. Utilizou-se o valor do VG, assim houve o subgrupo com anemia discreta (30 - 37\%), subgrupo com anemia moderada $(20-29 \%)$, subgrupo com anemia grave $(13-19 \%)$ e outro com anemia muito grave $(<13 \%)$.

Conforme preconizado por Jain (1993), a intensidade da resposta medular dos cães anêmicos foi estimada a partir da contagem absoluta de reticulócitos: resposta nula (até $6010^{9} / \mathrm{L}$ ); reticulocitose discreta $(60$ até $\left.15010^{9} / \mathrm{L}\right)$; reticulocitose moderada (150 até $\left.30010^{9} / \mathrm{L}\right)$ e reticulocitose intensa $\left(>30010^{9} / \mathrm{L}\right)$. A partir disso, o grupo de animais anêmicos também foi subdividido em subgrupos conforme a contagem de reticulócitos (resposta medular nula, reticulocitose discreta, reticulocitose moderada e reticulocitose intensa).

\section{Análise estatística}

$\mathrm{O}$ valor de referência para $\mathrm{RDW}-\mathrm{CV}$ foi obtido a partir da análise do grupo controle, considerando-se o valor médio, desvio-padrão e intervalo de confiança de 95\%. Para as comparações das variáveis entre os subgrupos de diferentes graus de anemia e resposta medular, após análise de normalidade (teste de Kolmogorov-Smirnov) e homocedasticidade (teste de 
Bartlett), foi utilizado o teste não paramétrico de KruskalWallis, considerando-se significativo o valor de $\mathrm{P}<0,05$. Utilizou-se o programa estatístico computacional InStat, versão 3.05. O subgrupo com reticulocitose intensa não foi comparado estatisticamente com os demais subgrupos, pois a quantidade de animais foi muito pequena. $\mathrm{O}$ subgrupo com anemia muito grave foi agregado ao subgrupo com anemia grave para análise estatística, também pelo mesmo motivo.

\section{RESULTADOS E DISCUSSAO}

\section{Valores de referência de $R D W-C V$ em cães normais}

$\mathrm{O}$ valor médio do RDW-CV encontrado na avaliação hematológica dos cães pertencentes ao grupo controle e utilizados na interpretação dos dados foi $13,4 \%$, com intervalo de confiança de 13,3 a 13,5\%. Classificados conforme a faixa etária, a referência para RDW-CV nos cães menores de um ano foi 13,2 -13,6\%, cães de 1 a 7 anos 13,2 -13,5 e cães >8 anos 13,5 -13,8.

Os valores de referência de RDW-CV do presente estudo foram inferiores aos dos demais estudos (NEIGER et al, 2002; FLAIBAN \& BALARIN, 2004; FERREIRA et al, 2009; SOUZA et al, 2012). Tal diferença pode ser justificada devido à utilização de diversos contadores de células automatizados, uma vez que já se sabe da necessidade de cada laboratório obter seus valores de referências com seus respectivos aparelhos, na tentativa de evitar falhas na interpretação dos resultados dos exames (HODGES \& CHRISTOPHER, 2011).

Embora o fabricante do contador de células automatizado utilizado no presente estudo (ABC Vet, Horiba $\mathrm{ABX}$ ) forneça valores de referência de fábrica para a espécie canina, os valores obtidos a partir da análise dos cães saudáveis (13,3-13,5\%) foram inferiores aos fornecidos pelo fabricante do aparelho (14-17\%). Essa diferença ressalta ainda mais a importância de cada laboratório obter seus próprios valores de referência.

\section{Valores de RDW-CV e VCM de acordo com o grau de anemia}

Dos 102 cães anêmicos analisados, 34 (33,3\%) apresentaram anemia discreta, $42(41,2 \%)$ anemia moderada, $20(19,6 \%)$ anemia grave e seis $(5,9 \%)$ anemia muito grave.

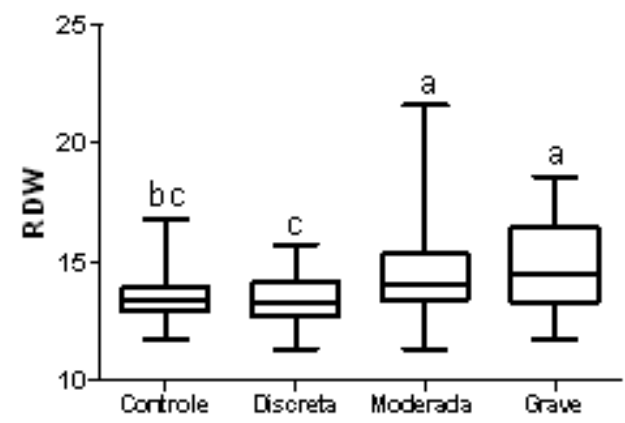

A comparação múltipla dos valores de VCM entre os grupos evidenciou que os cães com anemia discreta e moderada apresentaram significativamente $(\mathrm{p}=<0,001)$ valores menores de VCM que os animais do grupo controle. Já os animais com anemia grave não diferiram significativamente do grupo controle nem dos demais cães com anemia discreta e moderada (Figura 1). Os valores da mediana e do desvio-padrão dos grupos são descritos a seguir: controle (71,31 $\pm 3,63 \mathrm{fL})$, anemia discreta $(68,86 \pm 3,67 \mathrm{fL})$, anemia moderada $(69,18 \pm$ $4,63 \mathrm{fL})$ e anemia grave $(69,24 \pm 6,56 \mathrm{fL})$.

Já a comparação múltipla dos valores de RDW$\mathrm{CV}$ entre grupos e entre subgrupos resultou em diferença significativa $(\mathrm{p}=<0,01)$ entre o grupo controle e subgrupo com anemia discreta dos subgrupos com anemia grave e moderada (Figura 1). Os valores medianos e os desvios-padrão de RDW-CV são descritos a seguir: grupo controle $(13,40 \pm 0,78 \%)$, anemia discreta $(13,30 \pm 1,12 \%)$, anemia moderada $(14,05 \pm 1,98 \%)$ e anemia grave $(14,45 \pm 2,06 \%)$.

O aumento significativo dos valores de RDW$\mathrm{CV}$ apenas nos cães com anemia moderada e grave (Figura 1) sugere que as anemias discretas induzem pouca ou nenhuma resposta medular, haja vista que a ausência de reticulocitose nas anemias discretas não altera a variação no tamanho das hemácias e assim o valor de RDW-CV. Nesta condição de anemia discreta, a hipóxia talvez seja insuficiente para promover aumento de eritropoietina e consequentemente um aumento da produção de reticulócitos havendo apenas liberação de um número maior de eritrócitos maduros (COWGILL et al, 2003).

Há de se considerar também que algumas anemias discretas de origem nutricional, a exemplo da deficiência de ferro, além de não induzirem reticulocitose, podem gerar um padrão homogêneo de produção de eritrócitos (macro ou microcíticos) em quadros agudos que não alteram o RDW (WATSON \& CANFIELD, 1986). Portanto, nestes casos de anemia discreta não há alteração do $\mathrm{RDW}-\mathrm{CV}$, mas pode, em alguns casos, alterar significativamente o VCM sem que haja variação na amplitude das células. Sustentando esta hipótese, no presente estudo o VCM de cães com anemia discreta foi significativamente menor que o do grupo controle (Figura 1). Já nos cães com anemia grave (VG < 13\%) o VCM não diferiu dos cães controle, enquanto o RDW-CV aumentou significativamente.

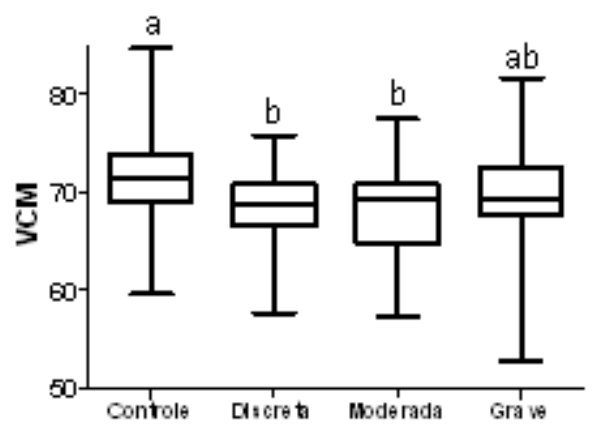

Figura 1 - Boxplot da distribuição do diâmetro eritrocitário (RDW-CV) e do volume corpuscular médio (VCM) de cães controle e com anemia discreta, moderada e grave (Kruskal-Wallis, $\mathrm{p}=<0,05$ para RDW-CV e $\mathrm{p}=<0,001$ para VCM). 
A utilização do RDW-CV se torna uma alternativa para avaliar a presença de anisocitose. Entretanto, valores elevados indicam um aumento na variação do diâmetro eritrocitário sem distinção se tal alteração se deve à presença de macrócitos, micrócitos ou ambos (PERRET et al, 2001). Já a combinação do RDW-CV com a análise morfológica e o valor do VCM permite a avaliação correta do tipo de alteração morfológica com uma maior sensibilidade.

\section{Relação dos valores de RDW-CV e VCM com o número de reticulócitos}

Dos 102 cães anêmicos analisados, 49 (48\%) apresentaram resposta nula, $35(34 \%)$ resposta discreta,
$14(14 \%)$ resposta moderada e quatro (4\%) resposta intensa.

O RDW-CV de cães portadores de anemia com resposta nula (reticulócitos $<60 \mathrm{mil} / \mu \mathrm{L}$ ) foi semelhante ao do grupo controle, enquanto que os cães com respostas discreta e moderada apresentaram significativamente $(\mathrm{p}=<0,01)$ valores mais elevados de RDW-CV, quando comparados ao grupo controle e aos animais com resposta nula (Figura 2). Os valores medianos e os desvios-padrão de RDW-CV são descritos a seguir: grupo controle $(13,40 \pm 0,78 \%)$, resposta nula $(13,40 \pm 1,95 \%)$, resposta discreta $(13,90$ $\pm 1,45 \%)$ e resposta moderada $(14,45 \pm 1,29 \%)$.
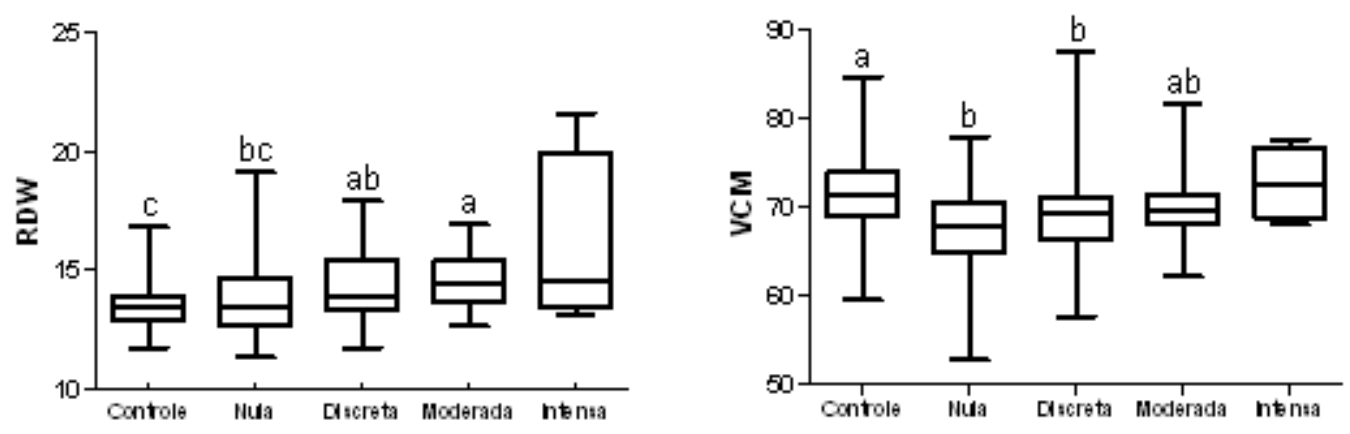

Figura 2 - Boxplot da distribuição do diâmetro eritrocitário (RDW-CV) e volume corpuscular médio (VCM) de cães controle e anêmicos de acordo com a taxa de reticulócitos: até $60 \mathrm{mil} / \mu \mathrm{L}$ (nula), discreta $(60-150 \mathrm{mil} / \mu \mathrm{L})$, moderada $(150-300 \mathrm{mil} / \mu \mathrm{L})$ e intensa $(>300 \mathrm{mil} / \mu \mathrm{L})($ Kruskal-Wallis, $\mathrm{p}=<0,05$ para RDW-CV e $\mathrm{p}=<0,01$ para VCM).

A alteração dos valores de RDW-CV acompanhou o aumento da taxa de reticulócitos. Entretanto, o maior número de reticulócitos circulantes na maioria dos casos não promoveu aumento significativo do VCM (Figura 2). Os valores medianos e os desvios-padrão do VCM são descritos a seguir: grupo controle $(71,31 \pm 3,63 \mathrm{fL})$, resposta nula $(67,86 \pm 4,98$ $\mathrm{fL})$, resposta discreta $(69,38 \pm 5,23 \mathrm{fL})$ e resposta moderada $(69,65 \pm 4,68 \mathrm{fL})$.

$\mathrm{O}$ fato de o VCM dos cães controle ter sido maior do que os dos cães nos diferentes graus de anemia e de reticulocitose (Figuras 1 e 2) sugere que parte dos cães anêmicos incluídos no estudo possuía uma população de eritrócitos mista, que contribuiu para o aumento do RDW-CV e redução dos valores de VCM. Este achado talvez se deva à presença de quantidade significativa de células microcíticas, não obstante a concomitante presença de reticulócitos. A presença de anisocitose mista ocorre comumente em resposta ao tratamento eficaz de anemias microcíticas de origem nutricional (HAROLD, 2010). Embora alguns indivíduos tenham apresentado valores extremos de VCM compatíveis com anemia macro e microcítica (Figura 2).

Nas anemias discretas (Figura 1) e com resposta nula (Figura 2) houve alteração significativa dos valores de VCM sem alteração dos valores de RDWCV em relação ao grupo controle. Estes achados em cães corroboram com estudos em humanos que afirmam que a acurácia para detecção da anisocitose eritrocitária aumenta quando o RDW é utilizado associado ao VCM (NEIGER et al, 2002).

\section{CONCLUSÃO}

O grau de anemia e de reticulocitose alteram de forma distinta os valores de RDW-CV e de VCM de cães.

O RDW-CV é um indicador de anisocitose mais sensível que o VCM e seu valor é diretamente proporcional ao grau de anemia e reticulocitose.

A sensibilidade para detecção de anisocitose em cães anêmicos é maior quando o VCM é associado ao RDW-CV.

A interpretação clínica adequada do RDW-CV depende do uso de valores de referência estabelecidos pelo próprio laboratório clínico.

Valores de referência para o coeficiente de variação da amplitude de distribuição eritrocitária (RDW- CV) para as amostras de cães analisadas no aparelho ABC Vet (Horiba ABX) é de 13,3 a 13,5\%.

\section{REFERÊNCIAS}

BALARIN, R. M. S.; FONTEQUE, J. H.; SOUZA, C. DE.; SAITO, M. E.; KOHAYAGAWA, A.; LOPES, R. S. Valores da amplitude de distribuição do tamanho dos eritrócitos (RDW - Red Cell Distribution Width) em equinos da raça puro sangue inglês (PSI) de ambos os sexos de 12 a 24 meses de idade Red Blood Cell Distribution Width (RDW) in thorougbred horses. Semina: Ciencias Agrárias, v.22, n.2, p.135-137, 2001. 
BESSMAN, J. D.; GILMER, P. R.; GARBNER, F. H. Improved Classification of Anemias by MCV and RDW. American Society of Clinical Pathologists, v.80, n.3, p.322-326, 1983.

COWGILL, E. S.; NEEL, J. A.; GRINDEM, C. B. Clinical application of reticulocyte counts in dogs and cats. Veterinary Clinical Small Animal Practice, v.33, p.1223-1244, 2003.

FERREIRA, G. S.; MASSON, G. C. I. H.; COSTA, E. D. C. P.; LIMA, D. J. S.; OLIVEIRA, G. S.; SOARES, F. N.; MENESES, A. M. C.; SOUZAL, N. F.; AZUMA, M. R.; SOUZA, A. M. A. Standardization of Red Blood Cell Distribution Widht (RDW) Values in Dogs From Northern Region of Brazil. In: 34th Congress Word Small Animal Veterinary Association, 2009, São Paulo. Proceedings... São Paulo, 2009.

FLAIBAN, K. K. M. C.; BALARIN, M. R. S. Estudo comparativo entre a amplitude de variação dos eritrócitos (RDW - Red Blood Cell Distribution Width) e o Volume Globular (VG), Volume Globular Médio (VGM) e a presença de anisocitose em extensão sanguínea em cães. Semina: Ciências Agrárias, v.25, n.2, p. 125-130, 2004

HAROLD, T. Laboratory and Clinical Diagnosis of Anemia. In: Schalm's Veterinary Hematology. 6.ed. Iowa: Blackwell Publishing, 2010. cap.24, p.152-161.

HODGES, J.; CHRISTOPHER, M. M Diagnostic accuracy of using erythrocyte indices and polychromasia to identify regenerative anemia in dogs. Journal of the American Veterinary Medical Association, v.238, n.11, p.1452-1458, 2011.

JAIN, N. C. Erythrocyte Physiology and Changes in Disease. In: Essentials of Veterinary Hematology. 1. ed. Philadelphia: Lea \& Febiger, 1993. Cap.7, p.133-158.

MONZON, C. M.; BEAVER, B. D.; DILLON, T. D. Evaluation of Erythrocyte Disorders With Mean Corpuscular Volume (MCV) and Red Cell Distribution Width (RDW). Clinical Pediatrics, v.26, n.12, p.632638, 1987.
NEIGER, R.; HADLEY, J.; PFEIFFER, D. U. Differentiation of dogs with regenerative and nonregenerative anaemia on the basis of their red cell distribution width and mean corpuscular volume. Veterinary Record. v.150, p.431-434, 2002.

PERRET, D.; TRUMEL,C.; DIQUÉLOU, A.; DOSSIN, O.; GUELFI, J. F. L'indice de distribution des globules rouges (IDR) chez le chien. Analyse de 1400 cas. Revue Medicine. Veretinaire, v.152, n.7, p.549-554, 2001.

SCHALM, O. W.; JAIN, N. C.; CARROL, E. J. Hematologic Techniques. In: Schalm's Veterinary Hematology. 3.ed. Philadelphia: Lea \& Febiger, 1975. cap 2, p. 20-86.

SIMEL, D.L.; DELONG, E.R.; FEUSSNER, J.R.; WEINBERG, J.B.; CRAWFORD, J. Erythrocyte Anisocytosis - Visual Inspection of Blood Films vs Automated Analysis of Red Blood Cell Distribution Width. Archive Internal Medicine, v.148, p.822-824, 1988.

SOUZA, A. M.; CAMARGO, M. B.; TENDLERLEIBELBACELLAR, D.; CAMPOS, S. D.; FILHO, R. A. T.; ALENCAR, N. X.; XAVIER, M. S.; MACIEIRA, D. B.; ALMOSNY, N. R. P. Age and sex influence in canine Red Cell Distribution Width (RDWCV and RDW-SD) values Revista Brasileira de Ciência Veterinária, v.19, n.2, p.90-93, 2012.

WATSON, A. D. J.; CANFIELD, P. J. Nutricional Deficiency Anemias. In: Schalm's Veterinary Hematology. 5. ed. Philadelphia: Lea \& Febiger, 1986. cap.32, p.190-195.

WEISER, M.G. Erythrocyte Volume Distribution Analysis in Healthy Dogs, Cats, Horses, and Dairy Cows. American Journal Veterinary Research, v.43, n.1, p.163-166, 1982. 